University of Rhode Island

DigitalCommons@URI

\title{
Medication-Assisted Treatment in Criminal Justice Agencies Affiliated with the Criminal Justice-Drug Abuse Treatment Studies (CJ-DATS): Availability, Barriers, and Intentions
}

\author{
Peter D. Friedmann \\ Randall Hoskinson Jr. \\ Michael Gordon \\ Robert Schwartz \\ Timothy Kinlock
}

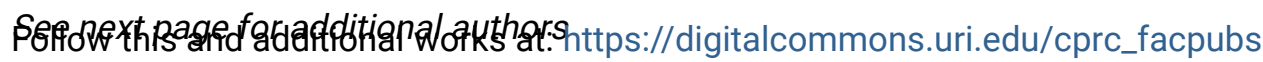

This is a pre-publication author manuscript of the final, published article.

Terms of Use

All rights reserved under copyright.

\footnotetext{
Citation/Publisher Attribution

Peter D. Friedmann MD, MPH, Randall Hoskinson Jr. MA, Michael Gordon DPA, Robert Schwartz MD, Timothy Kinlock PhD, Kevin Knight PhD, Patrick M. Flynn PhD, Wayne N. Welsh PhD, Lynda A. R. Stein PhD, Stanley Sacks PhD, Daniel J. O'Connell PhD, Hannah K. Knudsen PhD, Michael S. Shafer PhD, Elizabeth Hall PhD, Linda K. Frisman PhD \& for the MAT Working Group of CJ-DATS (2012) Medication-Assisted Treatment in Criminal Justice Agencies Affiliated with the Criminal Justice-Drug Abuse Treatment Studies (CJ-DATS): Availability, Barriers, and Intentions, Substance Abuse, 33:1, 9-18, DOI: 10.1080/ 08897077.2011.611460 Available at: http://dx.doi.org/10.1080/08897077.2011.611460
}

This Article is brought to you for free and open access by the Cancer Prevention Research Center at DigitalCommons@URI. It has been accepted for inclusion in Cancer Prevention Research Center Faculty Publications by an authorized administrator of DigitalCommons@URI. For more information, please contact digitalcommons-group@uri.edu. 


\section{Authors}

Peter D. Friedmann, Randall Hoskinson Jr., Michael Gordon, Robert Schwartz, Timothy Kinlock, Kevin Knight, Patrick M. Flynn, Wayne N. Welsh, Lynda A.R. Stein, Stanley Sacks, Daniel J. O'Connell, Hannah K. Knudsen, Michael S. Shafer, Elizabeth Hall, and Linda K. Frisman 


\title{
Medication-Assisted Treatment in Criminal Justice Agencies Affiliated with the Criminal Justice-Drug Abuse Treatment Studies (CJ-DATS): Availability, Barriers \& Intentions
}

\author{
Peter D. Friedmann, Randall Hoskinson Jr., Michael Gordon, Robert Schwartz, Timothy \\ Kinlock, Kevin Knight, Patrick M. Flynn, Wayne N. Welsh, Lynda A. R. Stein, Stanley Sacks, \\ Daniel J. O'Connell, Hannah K. Knudsen, Michael S. Shafer, Elizabeth Hall, and Linda K. \\ Frisman for the MAT Working Group of CJ-DATS
}

\section{Abstract}

Medication-assisted treatment (MAT) is underutilized in the treatment of drug-dependent, criminal justice populations. This study surveyed criminal justice agencies affiliated with the Criminal Justice Drug Abuse Treatment Studies (CJ-DATS) to assess use of MAT and factors influencing use of MAT. A convenience sample $(\mathrm{N}=50)$ of criminal justice agency respondents (e.g., jails, prisons, parole/probation, and drug courts) completed a survey on MAT practices and attitudes. Pregnant women and individuals experiencing withdrawal were most likely to receive MAT for opiate dependence in jail or prison, while those re-entering the community from jail or prison were the least likely to receive MAT. Factors influencing use of MAT included criminal justice preferences for drug-free treatment, limited knowledge of the benefits of MAT, security concerns, regulations prohibiting use of MAT for certain agencies, and lack of qualified medical staff. Differences across agency type in the factors influencing use and perceptions of MAT were also examined.

MAT use is largely limited to detoxification and maintenance of pregnant women in criminal justice settings. Use of MAT during the community reentry period is minimal. Addressing inadequate knowledge and negative attitudes about MAT may increase its adoption, but better linkages to community pharmacotherapy during the reentry period might overcome other issues, including security, liability, staffing and regulatory concerns. The CJ-DATS collaborative MAT implementation study to address inadequate knowledge, attitudes and linkage will be described.

\section{Introduction}

Medication assisted therapy (MAT) is underutilized in the treatment of alcohol- or opioiddependent, criminal justice populations(1-7) despite substantial evidence of its effectiveness in reducing opioid and alcohol use, $(8,9)$ criminal behavior and arrest,(10-13) and HIV risk behavior.(14,15) MAT here refers to the addition of pharmacotherapy to traditional substance abuse counseling in order to attenuate withdrawal symptoms, craving and/or the reinforcing euphoria resulting from alcohol or drug use. Opioid agonist treatment, for example, is rare in criminal justice settings in the United States despite widespread experience in correctional facilities throughout the world $(16,17)$ and expert consensus recommendations calling for its expansion.(18-20) National concern over the drug-crime relationship during the past 25 years has led to the predominance of criminal justice sanctions in lieu of therapeutic approaches like MAT, and this in turn has resulted in a vast

Corresponding Author: Peter D. Friedmann, M.D., M.P.H., Contact Information: Division of General Internal Medicine, Rhode Island Hospital, 593 Eddy Street, Providence, RI 02903. Tel: (401) 444-3347, Fax: (401) 444-5040, pfriedmann@lifespan.org. 
expansion of the drug-involved correctional population. $(21,22)$ The potential role of MAT for criminal justice populations is particularly germane today as numerous drug-involved inmates return to the community, and state budget crises provide impetus for evidence-based interventions like MAT to reduce the costs of rearrests and re-incarceration as well as the societal, human and health care costs associated with chronic substance dependence.

Increasing adoption and implementation of evidence-based treatments such as MAT in criminal justice settings is an overarching goal for the Criminal Justice Drug Abuse Treatment Studies (CJ-DATS). CJ-DATS is a national research program funded by the National Institute on Drug Abuse (NIDA). It includes ten Research Centers, their criminal justice partner organizations, and NIDA scientists. Many of the program's key questions reflect the need to understand organizational and systems issues that can facilitate or hinder implementation of effective drug treatment and other services for criminal justice populations. Particular interests include how agencies, sites or programs adopt and implement evidence-based practices across different stages of criminal justice processing, as well as how the implementation of evidence-based programs and practices can be improved to yield better client outcomes through increased access to and utilization of services. In preparation for the design of a multisite implementation trial, the MAT Working Group of CJ-DATS administered a preliminary planning survey to understand the availability of, need and readiness for, and barriers to MAT among partnering criminal justice agencies.

\section{Method}

\section{Study Population}

Data were collected on MAT policies and practices from 50 agencies located in 16 different locales within the United States, including 14 states, one federal district, and one unincorporated territory. Criminal justice agencies were comprised of four types: 18 jails, 12 prison or unified prison/jail systems, 12 probation or parole or unified probation/parole departments, and 8 drug courts. All 50 agencies dealt primarily with adult populations.

\section{Survey Development and Administration}

The survey was developed through a consensus- based approach, drawing on the expertise of our working group and prior correctional surveys. $(2,3)$ The survey was administered in August - October of 2009 to a convenience sample of criminal justice officials representing different criminal justice agencies working in partnership with the 10 CJ-DATS research centers. Investigators identified appropriate respondents (e.g. agency Administrators, Superintendents, Medical Directors) from CJ partners in jail, prison, probation, parole, and drug court settings. Some respondents completed the survey independently, while for others, telephone or in-person interviews were conducted. All research centers received either IRB exemption or expedited approval for this survey.

\section{Survey Description}

Items asked respondents to fill-in the percentages of the agency's population with opiate or alcohol dependence, as well as to check boxes to identify the populations provided with MAT (e.g. individuals experiencing opiate withdrawal, infected with HIV, receiving MAT in the community, and pregnant women) and the specific medications provided.

Respondents were also asked to indicate whether it would be possible to introduce or expand use of MAT for opiate addiction and alcohol (Yes/No response format). Additionally, respondents were asked to rate a series of 15 factors that might influence agency use of medication (e.g. administrative opposition, security concerns, liability issues, cost concerns) using a Likert-type scale where a rating of 0 indicated the factor was "Not important" and a rating of 5 indicated the factor was "Very important". Open ended questions asked 
respondents to elaborate on factors rated 4 or 5 . Finally, using a Likert-type scale where 0 represented "Not at all Likely" and 5 indicated "Very Likely", respondents were asked to indicate the likelihood that the agency would introduce or expand MAT in the next 2 years.

\section{Analysis}

Data analyses were conducted using SAS software (version 9.2). Fisher's exact test and ANOVA were used to compare current practices and descriptive data among the different types of criminal justice agencies. T-tests and logistic regression were used to compare agencies that currently provide MAT for maintenance with agencies that do not. Multiple regression analysis was used to examine the relationship between factors perceived to influence agency use of MAT and the likelihood of introducing or expanding MAT practices.

\section{Results}

Sites varied dramatically in the reported prevalence of opioid dependence (median, 18\%, interquartile range $8 \%-50 \%$ ) and alcohol dependence (median, 33\%, interquartile range $15 \%-63 \%)$ across sites, but these rates did not significantly vary by agency type. Of 18 jails, $15(83 \%)$ of jails and $10(83 \%)$ of 12 prisons reported providing MAT for opiate or alcohol dependence in a limited capacity [e.g., detoxification, administration to pregnant women only], compared with 3 (37.5\%) of 8 Drug Courts and 2 (17\%) of 12 Probation/Parole agencies (Table 1). Overall, methadone was the most commonly used medication ( 25 of 50 agencies), followed by clonidine (20 of 50 agencies), with buprenorphine (5 agencies, 10\%) and naltrexone (1 agency, $2 \%$ ) rarely provided.

Jails were the agency most likely to provide MAT, including clonidine, for opiate detoxification (15 [83\%] of 18) followed by prisons (8 [67\%] of 12) but only nine (50\%) of the jails and six prisons (50\%) provide methadone or buprenorphine for opiate detoxification. Regarding opiate maintenance, 9 of 18 jails reported providing methadone for pregnant women (none provided buprenorphine); and five (28\%) provided methadone or buprenorphine for persons already taking that medication. Regarding opiate maintenance in prison, 9 of 12 prisons or unified jail/prison agencies reported providing methadone or buprenorphine for pregnant women, three (25\%) for persons already taking methadone (overlapping with those who treat pregnant women), and only one of 12 prisons provided methadone maintenance for persons not already on methadone. One prison reported providing buprenorphine maintenance to persons switching from methadone, and one prison reported providing naltrexone for persons already taking naltrexone.

Probation/Parole agencies were least likely to provide MAT for either detoxification (0) or maintenance (1 of 12, 8\%). Provision of MAT was also rare for individuals who are leaving a criminal justice agency (e.g. leaving prison or ending probation), with only $12 \%$ of respondents ( 5 jails, 1 prison) indicating this practice. Of the 30 criminal justice agencies that provided MAT, 22 (73\%) indicated that they were also responsible for funding those MAT services. Jails and prisons were significantly more likely to fund MAT than drug courts or probation/parole agencies; only 2 of 12 probation/parole sites provide MAT, with just one responsible for funding.

Respondents rated the importance of fifteen factors thought to influence agency use of MAT (Table 2). The top six factors were: 1) Security concerns, 2) MAT is offered by community treatment programs, 3) Agency favors drug-free treatment over MAT, 4) Concerns about liability issues, 5) State or local regulations prohibit us from prescribing medications, and 6) Do not know of evidence of clinical effectiveness for criminal justice populations. 
There were significant differences between agency types. Agency preference for drug free treatment varied significantly by agency type $(\mathrm{F}=5.57, \mathrm{p}=.003)$. Post-hoc comparisons indicated that prisons tended to cite preference for drug free treatment as a greater factor in the use of MAT than drug courts $(\mathrm{p}=.001)$, jails $(\mathrm{p}=.08)$ and probation/parole agencies ( $\mathrm{p}$ $=.10)$. The rating of security concerns also differed significantly by agency type $(F=3.8, p$ $=.02$ ). Post-hoc comparisons indicated that prisons rated security concerns as a greater factor in use of MAT than probation/parole $(\mathrm{p}=.02)$ or drug courts $(\mathrm{p}=.08)$. Respondents were more likely to indicate their belief that jails as compared to than the other three agency types were prohibited from prescribing medications by state or local regulations $(\mathrm{F}=2.4, \mathrm{p}$ $=.09$ ). Drug courts and probation/parole agencies tended to cite lack of qualified medical staff more so than jails and prisons $(\mathrm{F}=2.7, \mathrm{p}=.06)$.

Data from these fifteen factors were also examined by whether or not the agency currently provides any MAT for maintenance (Table 3$)$. Lack of qualified staff $(\mathrm{F}=15.22, \mathrm{p}=.0003)$, inadequate information $(\mathrm{F}=7.10, \mathrm{p}=.01)$, staff objections $(\mathrm{F}=6.71, \mathrm{p}=.01)$ and liability concerns $(\mathrm{F}=3.95, \mathrm{p}=.05)$ were rated as significantly more important factors for agencies not providing MAT for maintenance than for those agencies that provide MAT maintenance. Agencies that currently provide MAT for maintenance also tended toward lower endorsement of the perception that "MAT just substitutes one drug for another" $(\mathrm{F}=2.90, \mathrm{p}$ $=.10)$, and that "opiate dependence is not a common problem within the agency" ( $\mathrm{F}=3.30$, $\mathrm{p}=.08$ ). Controlling for agency type, independent correlates of the current provision of MAT for maintenance were lack of qualified staff $(\chi 2=5.01, \mathrm{AOR}=.63(.42-.94), \mathrm{p}=.03)$ and staff objections to the use of MAT $(\chi 2=4.54, \mathrm{AOR}=.62(.40-.96), \mathrm{p}=.03)$ in a stepwise multiple logistic regression analysis.

In their open-ended remarks, some prison officials commented that MAT was impractical because prisoners are typically "clean" by the time they arrive at prison. Some jail officials agreed that starting MAT in jail was impractical because jail stays are often very short but, on the other hand, inmates are in withdrawal when they arrive. Remarks on regulatory concerns indicated that community agencies were often relied on for MAT because of regulation barriers which require special licensing for the administration of some MAT medications. Regarding security, comments centered abound concerns about possible diversion and inmates waiting in line for daily MAT administration. Liability concerns also focused on possible diversion and overdose. Respondents noted that agency lack of knowledge of MAT as an evidence-based practice occurred at various levels of the organization. Some described it as occurring agency-wide, while others depicted it at the medical staff or officer level. Funding-related comments cited the current budget climate, or, in the case of some community corrections agencies, the agency does not pay for any medical services.

Respondents were asked to indicate if it would be possible to introduce or expand MAT if evidence were available showing that MAT improved criminal justice outcomes. Of the 20 sites that do not currently provide MAT, $70 \%$ said it would be possible to introduce methadone, $70 \%$ buprenorphine, and $65 \%$ naltrexone. Sites that currently provided MAT $(\mathrm{n}=30)$ expressed similar interest with $63 \%$ indicating they would consider expanding methadone, $63 \%$ buprenorphine and $63 \%$ naltrexone. Overall, there were no significant differences between agencies with regards to types of MAT that might be possible to introduce or expand, or the likelihood of doing so in the next 2 years (Table 4).

Stepwise linear regression analysis was performed to examine the relationship between factors thought to influence agency use of MAT and the likelihood of expanding/introducing MAT in the next 2 years while controlling for agency type and current MAT use for maintenance. Only inadequate information about MAT in the agency $(\beta=.46)$ was 
independently related to a higher likelihood of expanding or/introducing $\mathrm{MAT}\left(\mathrm{R}^{2}=.35, \mathrm{~F}\right.$ $=6.57 \mathrm{p}=.001$ ).

\section{Discussion}

Almost three-quarters of the jails and prisons surveyed provide opioid pharmacotherapy for pregnant inmates and $60 \%$ use it for the management of opioid withdrawal. National surveys of state and federal correctional systems have noted that approximately half use methadone, predominately for pregnant inmates, short-term detoxification or chronic pain. $(2,3)$ Based on this availability, infrastructure appears to exist in many jails and prisons that might be expanded to serve other alcohol- and opioid-dependent criminal justice populations.(23) As in other studies,(3) current findings suggest that negative attitudes about MAT, concerns about security and local regulations that constrain the prescription of addiction pharmacotherapy would need to be addressed to facilitate such an expansion.(19)

The barriers cited varied by the type of setting. Respondents for jails displayed more concerns about state or local regulations, security, and that community treatment programs offer MAT. For prisons, security concerns, treatment philosophy (i.e. agency favors drugfree treatment, and that MAT was inconsistent with their treatment philosophy) and the availability of MAT from community programs emerged as issues. Drug courts cited concerns about liability, lack of qualified medical staff, and the difficulties with reimbursement. In probation and parole, the major issue that emerged was the availability of MAT from community treatment programs.

Of the approximately five million adults under community supervision,(20) over $15 \%$ are opioid-dependent, and alcohol use disorders are ubiquitous. $(24,25)$ In the current study, parole/probation respondents acknowledged opiate dependence in $17 \%$ of their clients and alcohol dependence in $35 \%$. So why is the use of MAT not more widespread in community corrections? One can speculate that the availability of MAT in some communities, inadequate information about the use of medication, negative attitudes toward MAT and a preference for abstinence only approaches throughout criminal justice(23) together might render agencies passive about ensuring adequate access to MAT.(19) Of note, agencies that reported inadequate information as an important factor in current MAT practices were more likely to be open to the possibility of introducing or expanding MAT than were those who reported inadequate information as less of a factor. This finding may signal that those who believe they have adequate knowledge in fact have a philosophical aversion based on common misperceptions and myths about MAT rather than valid evidence.

Community correctional agencies do not perceive a need to take on this service delivery role, as addiction pharmacotherapy could be obtained from local providers. Any expansion in community correctional settings would thus require increased collaboration with community MAT providers. Facilitating better linkages to community pharmacotherapy for appropriate individuals under community correctional supervision might overcome other issues, including security, liability, staffing or regulatory concerns. On this basis, the CJDATS collaborative is in the process of designing a field study to increase knowledge, attitudes and information about MAT and improve linkages to community MAT for opioidand alcohol-dependent clients on probation or parole supervision.

This study has several limitations. It is a convenience sample of criminal justice agencies that have voluntarily associated with a multisite correctional drug abuse research initiative. Volunteer bias would suggest that these systems may have better developed infrastructure, attitudes, and readiness for MAT than would a representative sample of agencies. If so, the infrastructure, attitudes, and readiness for MAT among other criminal justice agencies in the 
U.S. are likely to be less promising. For example, the "universe" of criminal justice agencies probably has an even lower likelihood of introducing or expanding MAT for opiate dependence in the next two years than the low-moderate likelihood (mean of two on a scale from zero to five) in these partnering agencies. The survey items were developed based on the expertise of our working group; despite their face validity, the psychometrics of the survey items are unknown. Finally, the extent to which community corrections agencies informally refer clients to community-based MAT was not determined by the survey.

Medication assisted treatment remains stigmatized and under-resourced in correctional settings. Nonetheless, existing infrastructure to provide addiction pharmacotherapy for pregnant women and detoxification provide a platform for incremental increases in MAT implementation.(19) Efforts to expand access to appropriate pharmacotherapy assisted treatment need to $(1)$ address inadequate information, philosophical aversion and negative attitudes about MAT through education and training about its benefits for the individual and society; (2) improve linkage to MAT for opiate- and alcohol- dependent persons under criminal justice supervision; and (3) target funding and resources toward the preferential use of evidence-based treatment modalities such as MAT.

\section{Acknowledgments}

This study was funded under a cooperative agreement from the National Institute on Drug Abuse, National Institutes of Health (NIDA/NIH), U.S. Department of Health and Human Services. The authors gratefully acknowledge the collaborative contributions by NIDA, the Coordinating Center (AMAR International, Inc.), and the Research Centers participating in CJ-DATS2 (Rhode Island Hospital, Brown University \& University of Rhode Island; the University of Connecticut; National Development and Research Institutes, Inc; Texas Christian University, Institute of Behavioral Research; University of Delaware, Center for Drug and Alcohol Studies; University of Kentucky, Center on Drug and Alcohol Research; University of California at Los Angeles, Integrated Substance Abuse Programs; Temple University, Department of Criminal Justice; Arizona State University; and Friends Research Institute). The authors thank Lori Ducharme, PhD, Services Research Branch, Division of Epidemiology, Services, and Prevention Research of NIDA/NIH for comments on the manuscript. The contents are solely the responsibility of the authors and do not necessarily represent the views of the NIDA/NIH, Department of Health and Human Services, other CJ-DATS participants or the Department of Veterans Affairs. More information on CJ-DATS can be found at http://CJ-DATS2.org.

\section{References}

1. Oser C, Knudsen HK, Staton-Tindall M, Taxman F, Leukefeld C. Organizational-level correlates of the provision of detoxification services and medication-based treatments for substance abuse in correctional institutions. Drug and Alcohol Dependence. 2009; 103S:S73-S81. [PubMed: 19108957]

2. Rich JD, Boutwell AE, Shield DC, Key RG, McKenzie M, Clarke JG, Friedmann PD. Attitudes and practices regarding the use of methadone in US state and federal prisons. Journal of Urban Health. 2005; 83(3):411-419. [PubMed: 15917502]

3. Nunn A, Zaller N, Dickman S, Trimbur C, Nijhawan A, Rich JD. Methadone and buprenorphine prescribing and referral practices in US prisons: results from a nationwide survey. Drug and Alcohol Dependence. 2009; 105(1-2):83-89. [PubMed: 19625142]

4. Taxman FS, Cropsey KL, Young DW, Wexler H. Screening, assessment, and referral practices in correctional settings: A national perspective. Criminal Justice and Behavior. 2007; 34:1216-1234. [PubMed: 18458758]

5. Volpicelli JR, Alterman AI, Hayashida M, O'Brien CP. Naltrexone in the treatment of alcohol dependence. Archives of General Psychiatry. 1992; 49(11):876-880. [PubMed: 1345133]

6. O’Malley SS, Jaffe AJ, Chang G, Schottenfeld RS, Meyer RE, Rounsaville B. Naltrexone and coping skills therapy for alcohol dependence. A controlled study. Archives of General Psychiatry. 1992; 49(11):881-887. [PubMed: 1444726] 
7. Kranzler HR, Gage A. Acamprosate efficacy in alcohol-dependent patients: summary of results from three pivotal trials. The American Journal on Addictions. 2008; 17(1):70-6. [PubMed: 18214726]

8. Amato L, Davoli M, Perucci CA, Ferri M, Faggiano F, Mattick RP. An overview of systematic reviews of the effectiveness of opiate maintenance therapies: available evidence to inform clinical practice and research. JSAT. 2005; 28(4):321-9.

9. Johnson BA. Update on neuropharmacological treatments for alcoholism: Scientific basis and clinical findings. Biochemical Pharmacology. 2008; 75(1):34-56. [PubMed: 17880925]

10. Ball, JC.; Ross, A. The effectiveness of methadone maintenance treatment: Patients, programs, services, and outcomes. New York: Springer-Verlag; 1991.

11. Johnson RE, Chutuape MA, Strain EC, Walsh SL, Stitzer ML, Bigelow GE. A comparison of levomethadyl acetate, buprenorphine, and methadone for opioid dependence. New England Journal of Medicine. 2000; 343:1290-1297. [PubMed: 11058673]

12. Joseph H, Stancliff S, Langrod J. Methadone maintenance treatment (MMT): A review of historical and clinical issues. The Mount Sinai Journal of Medicine. 2000; 67:347-364.

13. Schwartz RP, Jaffe JH, O'Grady K, Das B, Highfield DA, Wilson ME. Scaling-up Interim Methadone Maintenance: Treatment for one thousand heroin addicts. Journal of Substance Abuse Treatment. 2009; 37(4):362-367. [PubMed: 19540702]

14. Centers for Disease Control. Epidemiology of HIV/AIDS-United States, 1981. Morbidity and Mortality Weekly Report. 2006; 55:589-592. [PubMed: 16741494]

15. Metzger DS, Woody GE, McLellan AT, O’Brien CP, Druley P, Navaline H, et al. Human Immunodeficiency Virus Seroconversion among intravenous drug users in- and out-of-treatment: An 18-month prospective follow-up. Journal of Acquired Immune Deficiency Syndromes. 1993; 6(9):1049-1056. [PubMed: 8340896]

16. Jurgens R. Is the world finally waking up to HIV/AIDS in prisons? A report from the XV International AIDS Conference. Infectious Disease in Corrections Report. 2004:7.

17. McSweeney, T.; Turnbull, PJ.; Hough, M. Review of Criminal Justice Interventions for Drug Use in Other Countries. London: Criminal Policy Research Unit; 2002.

18. NIH Consensus Development Panel on Effective Medical Treatment of Opiate Addiction. Effective medical treatment of opiate addiction. Journal of the American Medical Association. 1998; 280:1936-1943. [PubMed: 9851480]

19. Centers for Disease Control. Substance Abuse Treatment for Injecting Drug Users: A Strategy with Many Benefits. Centers for Disease Control and Prevention; Atlanta, GA: 2002.

20. World Health Organization. Interventions to Address HIV in Prison: Drug Dependence Treatment. World Health Organization; Geneva: 2007. http://www.who.int/hiv/ied/EADrugTreatment.pdf

21. Couture, H.; Sabol, WJ. Prison inmates at midyear 2007 (NCJ 221944). Washington, D.C: Bureau of Justice Statistics, U.S. Department of Justice; 2008.

22. Greifinger, R. Thirty years since Estelle v. Gamble. In: Greifinger, R., editor. Public Health Behind Bars: From Prisons to Communities. Springer; New York: 2007.

23. McKenzie M, Nunn A, Zaller N, Rich JD. Overcoming obstacles to implementation of methadone for prisoners: implications for policy and practice. Journal of Opioid Management. 2009; 5(4): 189-95. [PubMed: 19736898]

24. Glaze, LE.; Bonzcar, TP. Probation and Parole in the US, 2008 (NCJ 228230). U.S. Department of Justice, Office of Justice Programs, Bureau of Justice Statistics; 2009.

25. Polcin DL, Greenfield TK. Factors associated with probation officers' use of criminal justice coercion to mandate alcohol treatment. The American Journal of Drug and Alcohol Abuse. 2003; 29(3):647-670. [PubMed: 14510045]

\section{APPENDIX A}

\section{AFFILIATIONS: MAT Working Group of CJ-DATS}

Peter D. Friedmann, MD, MPH; L.A.R. Stein, PhD; Frederic Friedman, EdD; Carmen Albizu-Garcia, MD; Randall Hoskinson, Jr. Rhode Island Unified Research Center, General 
Medicine Research Unit, Rhode Island Hospital, Providence, RI, University of Rhode Island, Kingston, RI and University of Puerto Rico, San Juan, PR.

Timothy Kinlock, Ph.D.; Michael Gordon, D.P.A.; Robert Schwartz, MD; Shannon Mitchell, PhD. Maryland Research Center, Friends Research Institute, Inc., Baltimore, MD.

Daniel J. O'Connell, PhD; Steven S. Martin, PhD; Holly Swan, MA. Mid- States Research Center, Center for Drug and Alcohol Studies, University of Delaware, Newark, DE.

Linda K. Frisman, PhD; Eleni Rodis. MS; Juliane Fenster, PhD, MPH; Deborah Henault, CADC. Connecticut Research Center, University of Connecticut, CT Department of Correction.

David Farabee, PhD; Elizabeth Hall, PhD. Pacific Coast Research Center, Integrated Substance Abuse Programs, University of California, Los Angeles

Patrick M. Flynn, PhD; Kevin Knight, PhD. Southwest Research Center, Institute for Behavioral Research, Texas Christian University, Fort Worth TX.

Wayne N. Welsh, PhD; Gary Zajac, PhD; Pennsylvania Research Center at Temple University, Philadelphia, PA; Commonwealth of Pennsylvania Department of Corrections.

Hannah K. Knudsen, PhD; Martin Hall, PhD, Jamison Duvall, PhD. Central States Research Center, Center for Drug and Alcohol Research, University of Kentucky, Lexington, KY.

Michael S. Shafer, PhD; Adrienne C. Pande, MA. Center for Applied Behavioral Research Policy, Arizona State University, Phoenix, AZ.

Stanley Sacks, PhD; Frank Pearson, PhD; Karen McKendrick, PhD. Rocky Mountains Research Center, National Development and Research Institute, Inc., New York, NY 


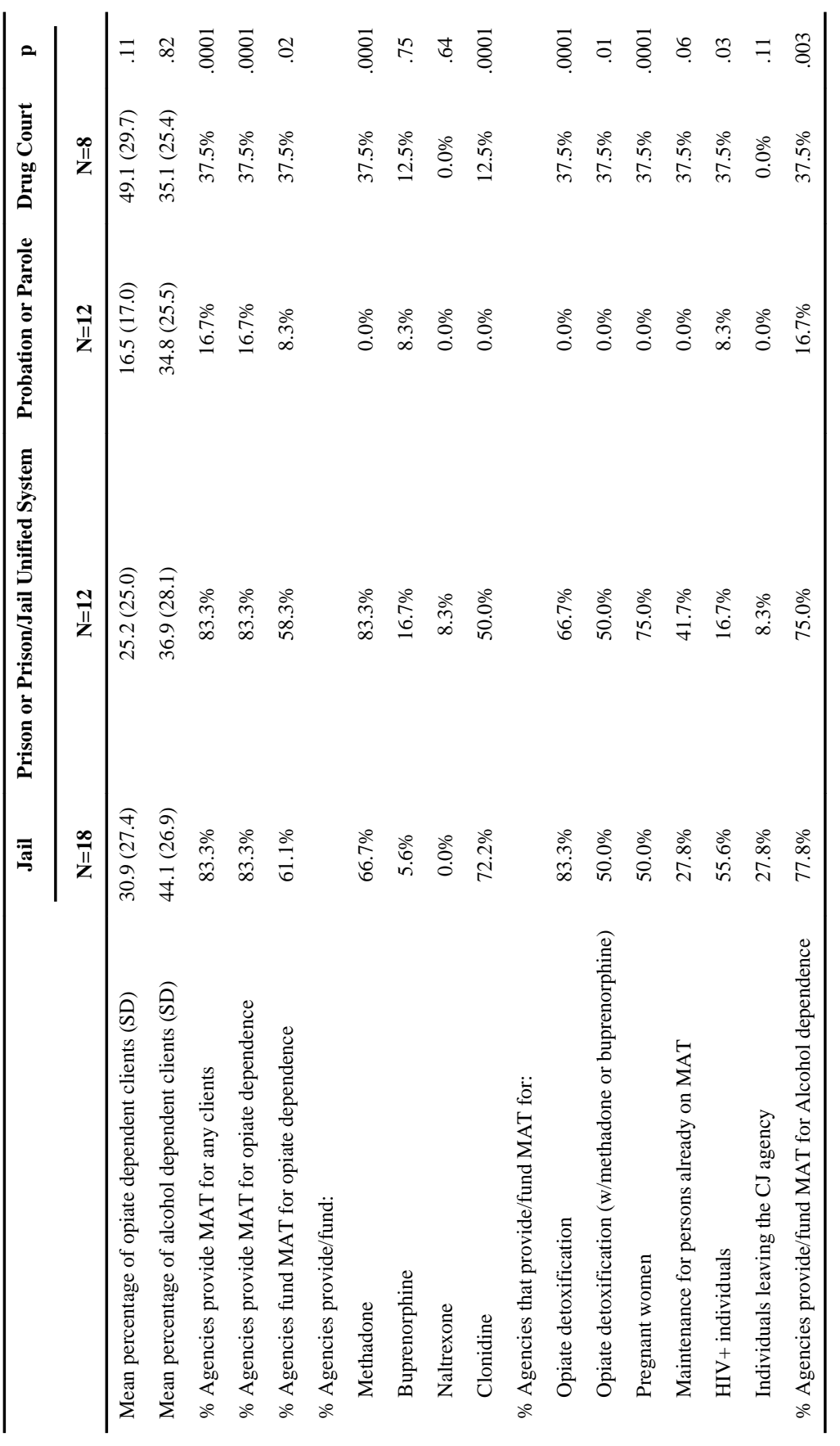




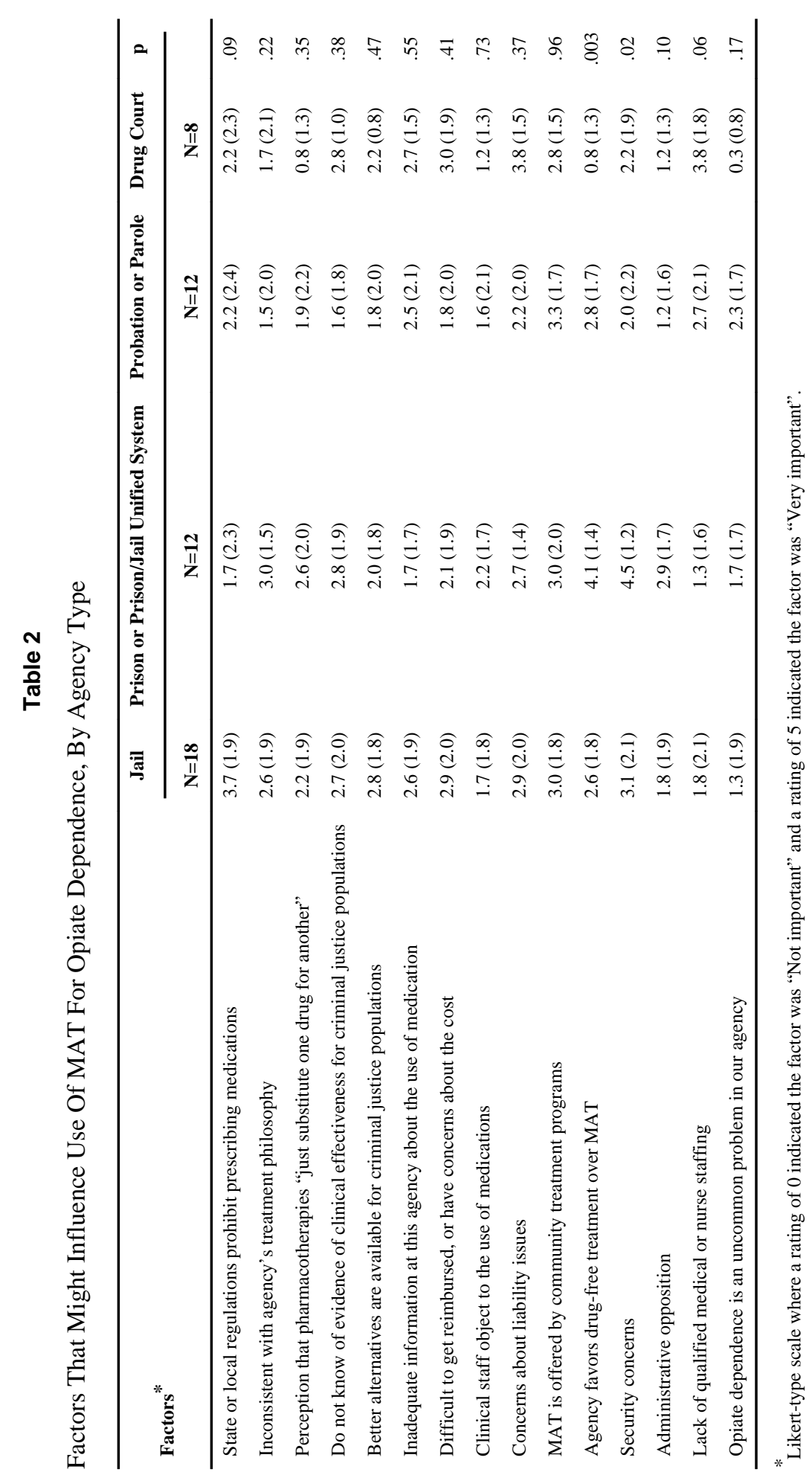


